\title{
Retarded Tempo of Physiological Development in Childhood Delays the Onset of the Metabolic Syndrome in Adulthood
}

\author{
Shumei S. Sun ${ }^{\mathrm{a}} \quad$ Adam P. Sima $^{\mathrm{a}} \quad$ John H. Himes ${ }^{\mathrm{b}}$ \\ aDepartment of Biostatistics, School of Medicine, Virginia Commonwealth University, Richmond, Va., and \\ ${ }^{b}$ Division of Epidemiology and Community Health, University of Minnesota, Minneapolis, Minn., USA
}

\section{Key Words}

Biostatistics · Cardiovascular health · Epidemiology ·

Metabolic syndrome · Obesity · Peak height velocity

\begin{abstract}
Using serial data from the Fels Longitudinal Study, we investigated the effects of early and late attainment of the peak height velocity (PHV) in childhood on the timing of the appearance of the metabolic syndrome later in life. We aimed to show if early attainment of PHV engenders greater risks for chronic diseases in boys than in girls. Therefore, we defined those boys and girls in sex-specific quartiles of the study population that were slowest to attain PHV as having a slow tempo of development, and those in the growth that most rapidly attained PHV as having a rapid tempo of development. Boys who experienced an early onset of PHV tended to have a higher risk for the metabolic syndrome, dyslipidemia and impaired fasting glucose than those who had late onset of PHV. Girls who had an early onset of PHV tended to develop more abdominal obesity than females who had a late onset of PHV.
\end{abstract}

C 2014 S. Karger AG, Basel

\section{KARGER}

(C) 2014 S. Karger AG, Base

0250-6807/14/0653-0175\$39.50/0

E-Mail karger@karger.com

www.karger.com/anm

\section{Introduction}

Restricting the caloric intake over a lifetime by $25-60 \%$ has been shown in a variety of animal models to lengthen lifespan [1-3]. One explanation for these observations is that caloric restriction leads to a decreased oxidation of nutrient substrates over a lifetime, resulting in a cumulative decrement in exposure of mitochondria, telomeres and other intracellular structures and organelles to reactive oxygen species [4-6]. However, more recently, Sinclair [7] proposed a unified theory of aging that involves activation of a set of genes that evolved to manage the cell economy during periods of nutritional stress.

Conversely, models that involve overfeeding of animals have been shown to accelerate the process of aging $[8,9]$. A possible explanation for this curtailment of lifespan is that of cumulative damage to intracellular structures and organelles caused by exposure to augmented levels of reactive oxygen species over a lifetime. These models are relevant to the present study of the influence of the tempo of physiological development on the rate of aging because they demonstrate that the rate of aging can be slowed or accelerated by caloric restriction or overfeeding. Although we do not have specific data on nutritional intake of the subjects in the Fels Longitudinal Study (FLS), we have complete serial records of their fat mass

Prof. Shumei S. Sun, PhD

Department of Biostatistics

School of Medicine, Virginia Commonwealth University

PO Box 980032, Richmond, VA 23298-0032 (USA)

E-Mail ssun@vcu.edu 
over a lifetime, determined by the direct methods of underwater weighing and dual-energy X-ray absorptiometry. These serial measurements of fat mass in each of the FLS subjects reflect their long-term energy balance at frequent intervals over a lifetime and may be linked to the tempo of physiological development in childhood and adolescence and to the appearance of metabolic and cardiovascular diseases later in life.

The negative effects of the accumulation of excess fat mass early in life have been elucidated by Sinha et al. [10], who demonstrated that obesity in childhood and adolescence is associated with impaired glucose tolerance and early appearance of type 2 diabetes mellitus, and by Berenson et al. [11], who showed that obesity early in life leads to atheromatous plaque deposition in the coronary arteries in the 2nd and 3rd decades of life. Garemo et al. [12] have shown increased insulin resistance in boys and girls who gained weight rapidly in the first 4 years of life, and Reinehr et al. [13] demonstrated that obese children have significantly thicker carotid intima-media thickness compared to nonobese children. An increased amount of body fat early in life also leads to early onset of puberty in girls [14-16].

Conversely, a low burden of body fat during the first 2 decades of life retards the tempo of physiological development. Warren and Goodman [17] and Warren and Shantha [18] showed that adolescent female gymnasts and ballet dancers who are in a negative energy balance or in a marginally positive energy balance have a delayed onset of menarche. More recently, Rozé et al. [19] showed that girls with anorexia nervosa and low body mass index (BMI) reach menarche at a mean age of 15.4 years, about 3 years later than the mean of girls in the FLS.

We have shown that early pubertal growth spurt predicts early attainment of adult insulin levels and lipid profiles [20]. Sun and Schubert [21] previously ascertained the influence of a prolonged juvenile state on delaying the onset of the metabolic syndrome, cardiovascular disease and type 2 diabetes mellitus later in life. They found that children who matured relatively early tended to have greater BMI, waist circumference and percent of body fat, and were more likely to have adverse cardiovascular risk profiles than children who matured late. The differences in these risk factors between early and late maturers were significant for percent body fat, fasting plasma triglycerides and fasting plasma insulin at age 18 35 years.

In this study, we ascertain the influence of a prolonged juvenile state, i.e. a retarded tempo of physiological development, on delaying the onset of the metabolic syndrome later in life. We link risk factors to this common but unhealthy feature of aging to childhood tempo of physiological development. The tempo of physiological development is determined in each subject by documenting his or her age at the time of peak height velocity (PHV), the age at attainment of the maximum velocity of growth in height during adolescence. Specifically, we test two hypotheses:

Hypothesis 1: That boys and girls with a relatively shorter or curtailed juvenile state will have higher levels of waist circumference/height as adults than boys and girls with a prolonged juvenile state.

Hypothesis 2: That boys and girls with a curtailed juvenile state will have lower adult levels of fasting plasma HDL cholesterol, higher systolic and/or diastolic blood pressures, and higher fasting plasma triglyceride and fasting plasma glucose concentrations as adults than boys and girls with a prolonged juvenile state.

\section{Subjects and Methods}

\section{Study Sample}

The study sample consists of 431 adults (213 males and $218 \mathrm{fe}$ males) in the FLS who have sufficient childhood height data recorded to capture the age at PHV as well as sufficient serial metabolic syndrome risk factor data collected in the same subjects later in life. Parameters used to assess the metabolic syndrome include waist circumference, HDL cholesterol, triglycerides, systolic and diastolic blood pressure, and fasting plasma glucose.

\section{Measurements}

The FLS has enrolled cohorts of 15-25 newborn infants every year to the present, beginning in 1930. Participants were examined at birth and at 1, 3, 6, 9 and 12 months of age, then every 6 months for 18 years and biennially thereafter. Anthropometric parameters and blood pressure were measured and family health history ascertained. Beginning in 1976, body composition, fasting plasma lipids and lipoproteins were measured, and lifestyle variables such as cigarette smoking and physical activity were recorded for participants 8 years and older. Approximately $8 \%$ of the FLS participants have been lost to follow-up, but their body composition data at their last visit did not differ from the $92 \%$ remaining in the study. Measurement reliability in the FLS is excellent, and reliability coefficients for most of the variables are well above $90 \%$.

Weight, stature and abdominal circumference were measured using standardized procedures similar to the recommendations of the Airlie Consensus Conference [22]. Weight is measured to the nearest $10 \mathrm{~g}$ and stature is measured to the nearest millimeter. The waist circumference measurement is recorded to the nearest millimeter. Systolic blood pressure measurements were measured by trained technicians with the participant seated, using a standard mercury sphygmomanometer with the procedure recommended by the American Heart Association and the National Institutes of Health [23]. Serial fasting plasma HDL cholesterol and triglycerides were measured annually near the time of the participants' 

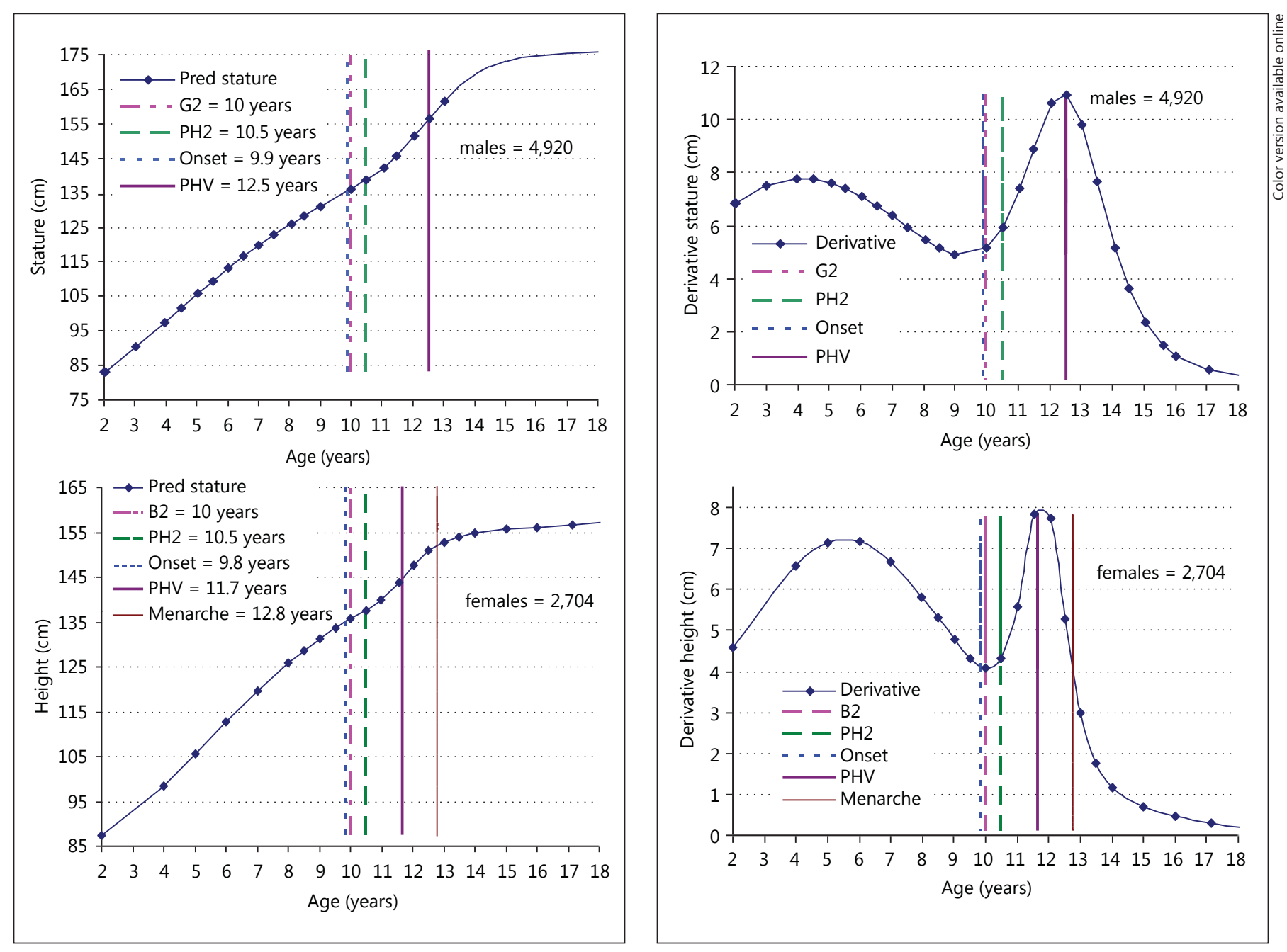

Fig. 1. Observed (dots) and predicted (line) height from 2 to 18 years of age.

birthdays beginning at the age of 8 years. These parameters were measured at the Medical Research Laboratory in Cincinnati. Fasting plasma levels of glucose and insulin were also measured using conventional methods. All procedures were approved by the Institutional Review Boards of the Virginia Commonwealth University and Wright State University.

\section{Quantifying Age at PHV}

A triple logistic model was applied to individual semi-annual data for height from 2 to 18 years of age to derive the timing of the onset of the pubertal growth spurt and the age at PHV [21]:

$$
h(t)=\frac{a_{1} q}{1+e^{-b_{1}\left(t-c_{1}\right)}}+\frac{a_{1} p}{1+e^{-b_{2}\left(t-c_{2}\right)}}+\frac{f-a_{1}}{1+e^{-b_{3}\left(t-c_{3}\right)}},
$$

where $h(t)=$ height at time $t, a_{1}=$ contribution of prepubertal growth to mature height, $b_{1}=$ slope of the early childhood component at maximum velocity, $c_{1}=$ age at maximum velocity of the early-childhood component; $b_{2}=$ slope of the middle-childhood component at maximum velocity, $c_{2}=$ age at maximum velocity of the middle-childhood component, $p=$ proportion of prepubertal growth due to the middle-childhood component, $q=1-p$, $f-a_{1}=$ contribution of the adolescent component to mature stature, $b_{3}=$ slope of the adolescent component at maximum velocity and $c_{3}=$ age at maximum velocity of the adolescent component. The growth parameters that quantify the timing at PHV were derived from the coefficients in the fitted models.

\section{Rate of Maturation}

We define those boys and girls whose age of attainment of PHV is in the highest quartile of the overall FLS sample as having a prolonged juvenile state. Conversely, we define those boys and girls whose age of attainment of PHV is in the lowest percentile of the study population as having a curtailed juvenile state. The cutoffs for lower and upper quartiles are 12.8 and 14.3 years for males and 10.8 and 12.1 years for females, respectively. 
Table 1. Summary information for age at PHV estimated from the triple logistic models and age at the diagnosis of the metabolic syndrome

\begin{tabular}{lcccccc}
\hline & $\mathrm{n}$ & Mean & SD & 25th & 50 th & 75 th \\
\hline $\begin{array}{l}\text { Age at PHV } \\
\quad \text { Males }\end{array}$ & 213 & 13.5 & 1.3 & 12.9 & 13.7 & 14.3 \\
$\quad$ Females & 218 & 11.5 & 0.9 & 11.0 & 11.6 & 12.1 \\
\hline $\begin{array}{l}\text { Age at the diagnosis of the metabolic syndrome } \\
\text { Males }\end{array}$ & 158 & 41.3 & 0.9 & 30.2 & 40.0 & 53.0 \\
Females & 154 & 43.0 & 15.7 & 29.0 & 40.7 & 56.8 \\
\hline
\end{tabular}

Table 2. Prevalence of the metabolic syndrome and each risk factor separately by sex

\begin{tabular}{lllr}
\hline Risk factor & \multicolumn{2}{c}{ Prevalence, $\%$} & p value \\
\cline { 2 - 3 } & male & female & \\
\hline Metabolic syndrome & 27.7 & 20.7 & 0.092 \\
Waist circumference & 29.1 & 44.7 & $<0.001$ \\
Blood pressure & 35.2 & 20.3 & $<0.001$ \\
Triglycerides & 40.4 & 29.8 & 0.022 \\
HDL cholesterol & 37.1 & 37.6 & 0.910 \\
Glucose & 36.8 & 20.7 & $<0.001$ \\
\hline
\end{tabular}

\section{Adult Metabolic Syndrome}

The Third Report of the National Cholesterol Education Program (NCEP) Expert Panel on Detection, Evaluation, and Treatment of High Blood Cholesterol in Adults (Adult Treatment Panel, ATP III) [24] provides a working definition of the metabolic syndrome in adults as having a cluster of three, four or five risk factors that exceed criterion values: namely, waist circumference $>102 \mathrm{~cm}$ for men and $>88 \mathrm{~cm}$ for women; blood pressure $>130 />85$ $\mathrm{mm} \mathrm{Hg}$; plasma triglyceride level $>150 \mathrm{mg} / \mathrm{dl}$; plasma HDL cholesterol level $<40 \mathrm{mg} / \mathrm{dl}$ for men and $<50 \mathrm{mg} / \mathrm{dl}$ for women, and fasting plasma glucose $>110 \mathrm{mg} / \mathrm{dl}$. Kahn and colleagues [25] recommended that the criterion value for fasting plasma glucose be lowered to $100 \mathrm{mg} / \mathrm{dl}$, and we have done so in our analyses. The age at the first diagnosis of each of the metabolic syndrome risk factors was identified. These estimates are sufficient for the present analyses.

\section{Statistical Methods}

The ages at PHV and the age at the onset of the metabolic syndrome in the cohort of interest are summarized, separately for males and females, with means and standard deviations (SD), and the 25th, 50th and 75th percentiles. The mean onset ages for the metabolic syndrome are reported separately in subjects who had curtailed and prolonged juvenile states. The prevalence of the metabolic syndrome and for each of the five diagnostic risk factors are summarized by percentages separately for males and females. The difference in the prevalence between the sexes is tested using Pearson's $\chi^{2}$ test of homogeneity.
The influence of the age at PHV was assessed by considering only the subjects who had either a curtailed or prolonged juvenile state. This resulted in a subsample of 211 subjects (107 males and 104 females). Pearson's $\chi^{2}$ tests of association and Kaplan-Meier survival curves were used to assess how the age at PHV influenced the age at the onset of each of the five risk factors separately for males and females. The Nelson-Aalen cumulative distribution function was also plotted separately for males and females, as were the median survival times with the corresponding 95\% confidence intervals (CI). The difference in median survival times between the PHV groups was tested using the log-rank test. All statistical tests were performed at the $\mathrm{p}=0.05$ level using SAS version 9.3.

\section{Results}

\section{Age at $\mathrm{PHV}$}

The triple logistic model was applied to each individual's serial height data. Figure 1 illustrates examples for a randomly selected boy and girl. The upper left and right panels present distance trajectory in the boy and girl, respectively, with observed serial data and predicted values for height using the triple logistic models. The lower panels present the corresponding velocity curves for the same boy and girl. The individual fitted growth trajectory allows the estimation of the onset of the pubertal growth spurt and the age at PHV. The boy started the pubertal growth spurt at age 9.9 years and reached his PHV at age 12.8 years, while the girl started her pubertal spurt at age 9.8 years and reached her PHV at age 11.4 years. The descriptive statistics for the age at PHV are illustrated in the upper part of table 1.

\section{Metabolic Syndrome}

The distributions for the earliest age at the onset of unhealthy events, i.e. the metabolic syndrome, low HDL cholesterol, and high triglycerides, glucose, blood pressure, and waist circumference, are shown in the lower part of table 1 . The overall mean age at the onset of the metabolic syndrome is 41.3 years for men and 43.0 years for women. The prevalence of the metabolic syndrome is $27.7 \%$ in men and $20.7 \%$ in women (table 2). Both men and women who had a curtailed juvenile state had an earlier age of onset of the metabolic syndrome (males: mean $=43.8$ years; females: mean $=$ 45.9 years) than subjects who had a prolonged state (males: mean $=50.0$ years; females: mean $=56.4$ years). There is a difference between men and women in the individual prevalence of risk factors that contribute to the metabolic syndrome. Women had significantly greater prevalence of abdominal obesity (44.7\%) than men $(29.1 \%)$. Men had significantly greater prevalence 
Table 3. Frequencies, percentages and median survival times of risk status over the categorized age of PHV separately by sex

\begin{tabular}{|c|c|c|c|c|}
\hline \multirow[t]{2}{*}{ PHV groups } & \multirow[t]{2}{*}{ Healthy } & \multicolumn{2}{|c|}{ At risk } & \multirow{2}{*}{$\begin{array}{l}\text { Median survival } \\
(95 \% \mathrm{CI})\end{array}$} \\
\hline & & $\mathrm{n}$ & $\%$ & \\
\hline \multicolumn{5}{|l|}{ Male } \\
\hline \multicolumn{5}{|c|}{ Metabolic syndrome ${ }^{\mathrm{a}}$} \\
\hline Early & 37 & 17 & 31.5 & $54.6(43.3-62.2)$ \\
\hline Late & 40 & 13 & 24.5 & $65.7(56.5-73.6)$ \\
\hline \multicolumn{5}{|c|}{ Waist circumference } \\
\hline Early & 42 & 12 & 22.2 & $54.6(54.3-64.2)$ \\
\hline Late & 35 & 18 & 34.0 & $58.9(52.5-58.5)$ \\
\hline \multicolumn{5}{|c|}{ Blood pressure } \\
\hline Early & 35 & 19 & 35.2 & $54.3(41.6-62.6)$ \\
\hline Late & 32 & 21 & 39.6 & $56.5(48.2-61.0)$ \\
\hline \multicolumn{5}{|l|}{ Glucose $^{\mathrm{a}}$} \\
\hline Early & 33 & 21 & 38.9 & $47.1(42.0-58.1)$ \\
\hline Late & 36 & 16 & 30.8 & $59.9(52.3-68.5)$ \\
\hline \multicolumn{5}{|l|}{ Triglycerides $^{\mathrm{a}}$} \\
\hline Early & 29 & 25 & 46.3 & $43.5(41.6-57.5)$ \\
\hline Late & 34 & 19 & 35.9 & $58.9(49.6-65.7)$ \\
\hline \multicolumn{5}{|l|}{$\mathrm{HDL}^{\mathrm{b}}$} \\
\hline Early & 27 & 27 & 50.0 & $43.2(36.6-62.2)$ \\
\hline Late & 37 & 16 & 30.2 & $65.7(\mathrm{NA})^{\mathrm{c}}$ \\
\hline \multicolumn{5}{|c|}{ Female } \\
\hline \multicolumn{5}{|c|}{ Metabolic syndrome } \\
\hline Early & 36 & 10 & 21.7 & $65.5(51.3-74.9)$ \\
\hline Late & 45 & 12 & 21.1 & $60.6(57.8-75.1)$ \\
\hline \multicolumn{5}{|c|}{ Waist circumference ${ }^{\mathrm{b}}$} \\
\hline Early & 19 & 27 & 58.7 & $46.1(35.4-56.8)$ \\
\hline Late & 37 & 20 & 35.1 & $58.6(51.3-71.2)$ \\
\hline \multicolumn{5}{|c|}{ Blood pressure } \\
\hline Early & 40 & 6 & 13.0 & $66.5(51.3-71.9)$ \\
\hline Late & 42 & 15 & 26.3 & $59.4(56.9-74.8)$ \\
\hline \multicolumn{5}{|l|}{ Glucose } \\
\hline Early & 36 & 9 & 20.0 & $65.5(47.4-74.9)$ \\
\hline Late & 48 & 9 & 15.8 & $\mathrm{NA}(\mathrm{NA})^{\mathrm{c}}$ \\
\hline \multicolumn{5}{|l|}{ Triglyceride } \\
\hline Early & 31 & 15 & 32.6 & $57.3(41.5-74.9)$ \\
\hline Late & 38 & 20 & 34.5 & $60.0(51.3-63.8)$ \\
\hline \multicolumn{5}{|l|}{ HDL } \\
\hline Early & 25 & 21 & 45.7 & $46.1(38.7-65.5)$ \\
\hline Late & 36 & 22 & 37.9 & $63.8(42.0-75.1)$ \\
\hline
\end{tabular}

${ }^{\mathrm{a}} \log$-rank test: $0.01<\mathrm{p}<0.001{ }^{\mathrm{b}} \log$-rank/Pearson's $\chi^{2}: 0.01<$ $\mathrm{p}<0.001 .{ }^{\mathrm{c}}$ Estimates do not exist due to heavy censoring.

of elevated blood pressure (35.2\%) than women (20.3\%). Men also had a significantly greater risk of having elevated plasma triglycerides (40.4\%) than women (29.8\%). In addition, men (36.8\%) had a significantly greater prevalence of elevated plasma glucose concentration than women $(20.7 \%)$.

Onset of the Metabolic Syndrome in Adulthood

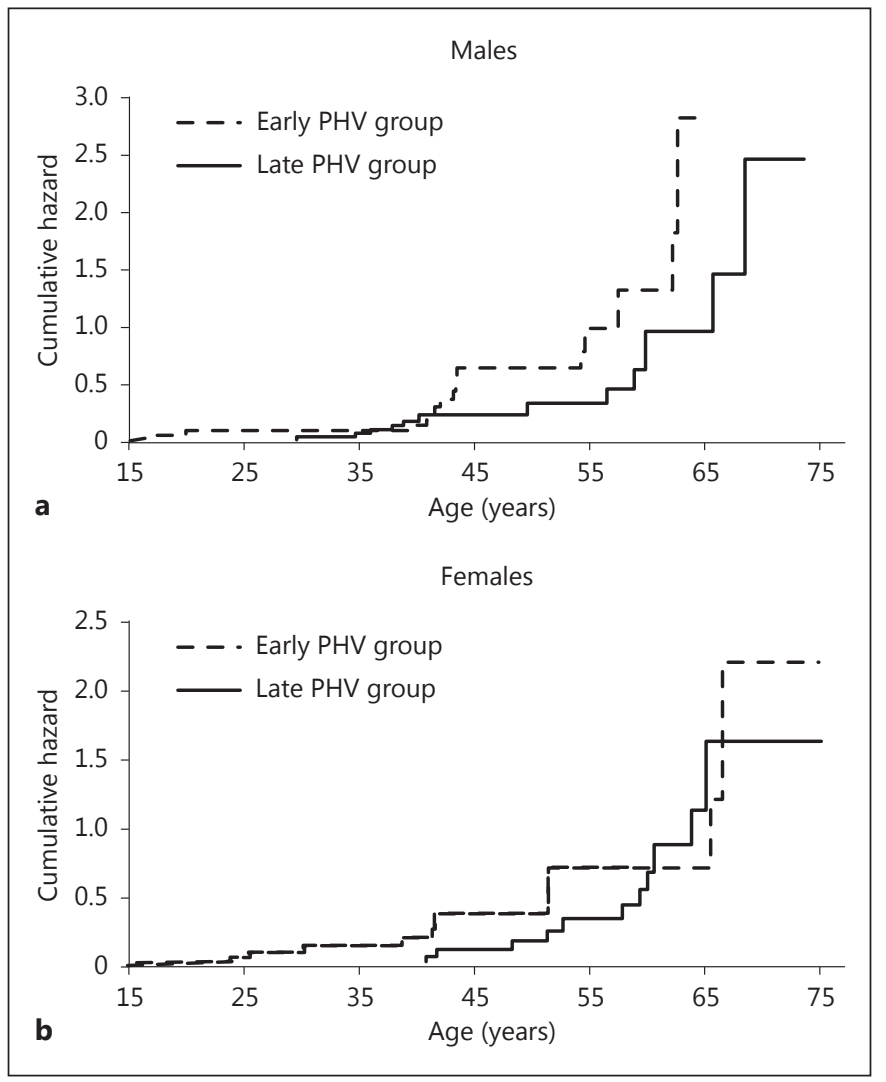

Fig. 2. Cumulative risk of developing the metabolic syndrome for curtailed versus prolonged juvenile state. $\log$-rank test $\mathrm{p}=0.014$ (a) and $\mathrm{p}=0.359$ (b), early vs. late groups.

\section{The Effects of Age at PHV on Risk Factors}

Table 3 lists the prevalence of the metabolic syndrome and each of the five risk factors by the timing of PHV separately for males and females. The prevalences of all the cardiovascular risk factors show no uniform pattern with respect to either the timing of PHV or sex. Nominally, early maturing males had a higher prevalence of the metabolic syndrome $(31.5 \%)$ than late maturers $(24.5 \%)$, although this difference did not reach statistical significance $(\mathrm{p}=$ 0.423). No difference was observed in the prevalence of the metabolic syndrome between females in the curtailed $(21.7 \%)$ and prolonged $(21.1 \%)$ juvenile state $(\mathrm{p}=0.933)$. Female subjects who had a curtailed juvenile state are more likely than late maturers to have an unhealthy waist circumference $(\mathrm{p}=0.017)$. Males with an early age of PHV tended to have a higher risk of having levels of HDL cholesterol below the cutoff points compared to those with a late age of PHV ( $p=0.037)$. No other statistically significant difference in the prevalence of the risk factors was observed between subjects with curtailed and prolonged juvenile states. 


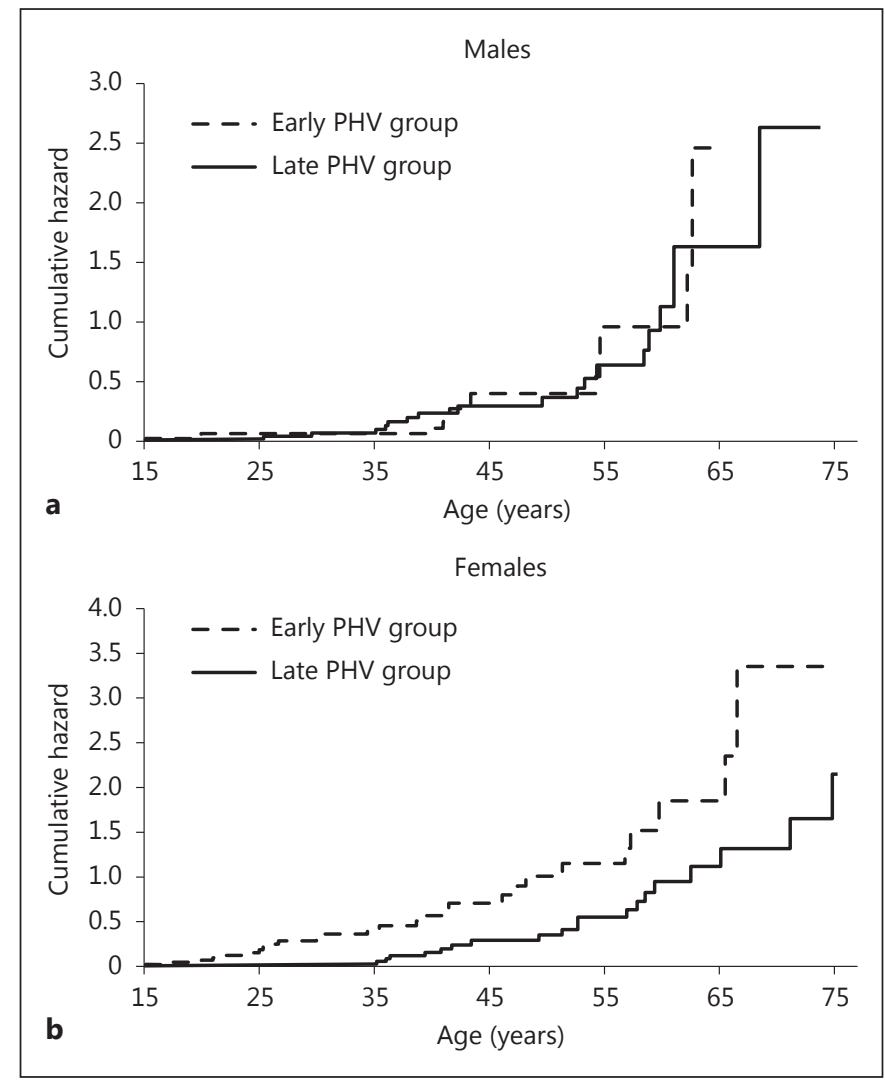

Fig. 3. Cumulative risk of developing abdominal obesity (waist circumference) for curtailed versus prolonged juvenile state. log-rank test: $\mathrm{p}=0.610(\mathbf{a})$ and $\mathrm{p}=0.002(\mathbf{b})$, early vs. late groups.

The cumulative hazard functions for metabolic syndrome can be seen in figure 2 and the cumulative hazard functions for the other risk factors can be seen in figures $3-7$. The estimated median age at onset of each of the risk factors can be seen in table 3 with the corresponding 95\% CI. The $\mathrm{p}$ values from the log-rank test are shown in figures 2-7 as well as in table 3. Generally, subjects who had an early timing of PHV had earlier onset of the metabolic syndrome and the corresponding risk factors. For the metabolic syndrome, males who had an early PHV had an earlier onset of the metabolic syndrome $(p=0.031)$ than those who had a late PHV, indicating a cohort at higher risk of this condition. Males who were in a curtailed juvenile state also had a higher risk of having unhealthy fasting plasma glucose, triglyceride and $\mathrm{HDL}$ cholesterol levels ( $\mathrm{p}=0.009,0.009$ and 0.002 , respectively). Females with either a curtailed or a prolonged juvenile state exhibited no difference in the age at onset of the metabolic syndrome $(p=0.580)$. However, females who had a curtailed juvenile state were more at risk of having

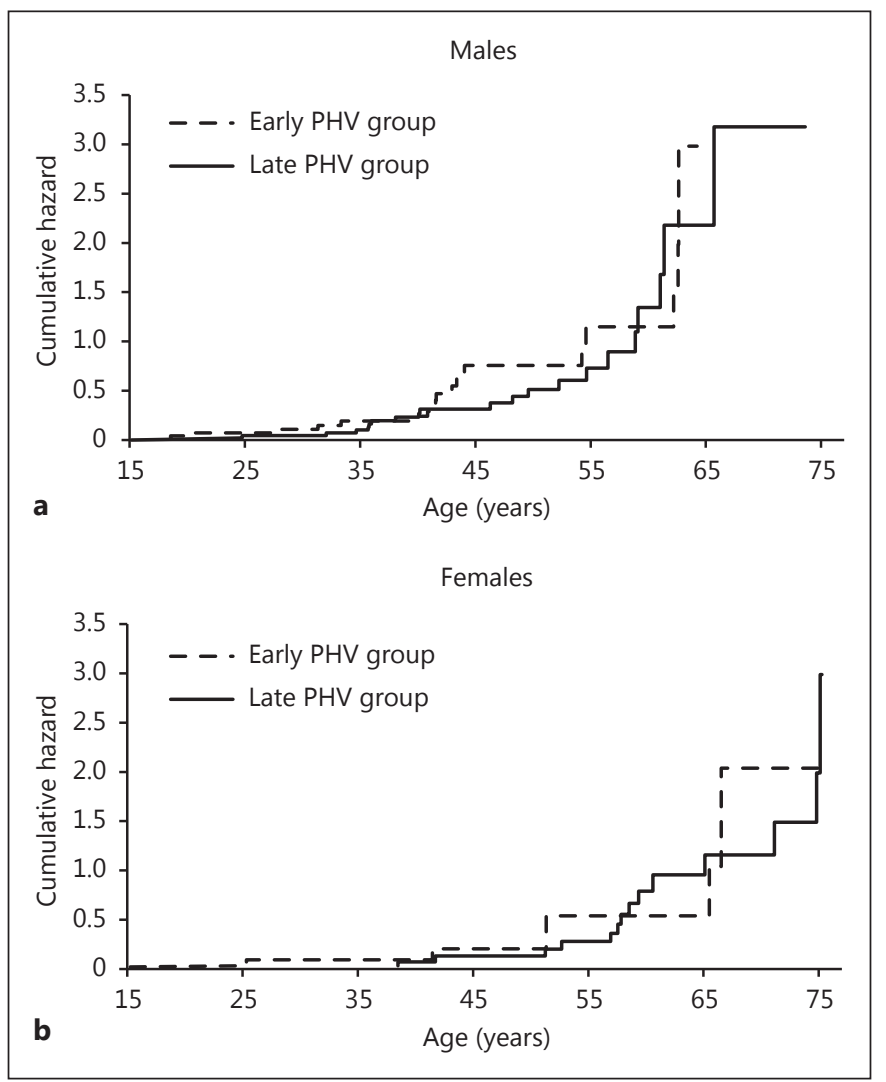

Fig. 4. Cumulative risk of developing elevated blood pressure for curtailed versus prolonged juvenile state. $\log$-rank test: $\mathrm{p}=0.318$ (a) and $\mathrm{p}=0.873$ (b), early vs. late groups.

a higher waist circumference than those who had a prolonged juvenile state $(\mathrm{p}=0.002)$. No other differences in the age at onset of any of the risk factors were observed for either males or females.

\section{Discussion}

The innovative approach taken in this study includes the application of time-to-event models to relate the age at PHV to the onset of the metabolic syndrome later in life. The timing of attaining PHV was determined by fitting individual serial data for height from 2 to 18 years to triple logistic models. No previously published studies linking the tempo of physiological development in the first 2 decades of life to the onset of the metabolic syndrome were found.

The present study takes advantage of a unique data set which permits the examination of relationships from variables collected in childhood to those collected in adulthood. Embedded within this large collection of se- 


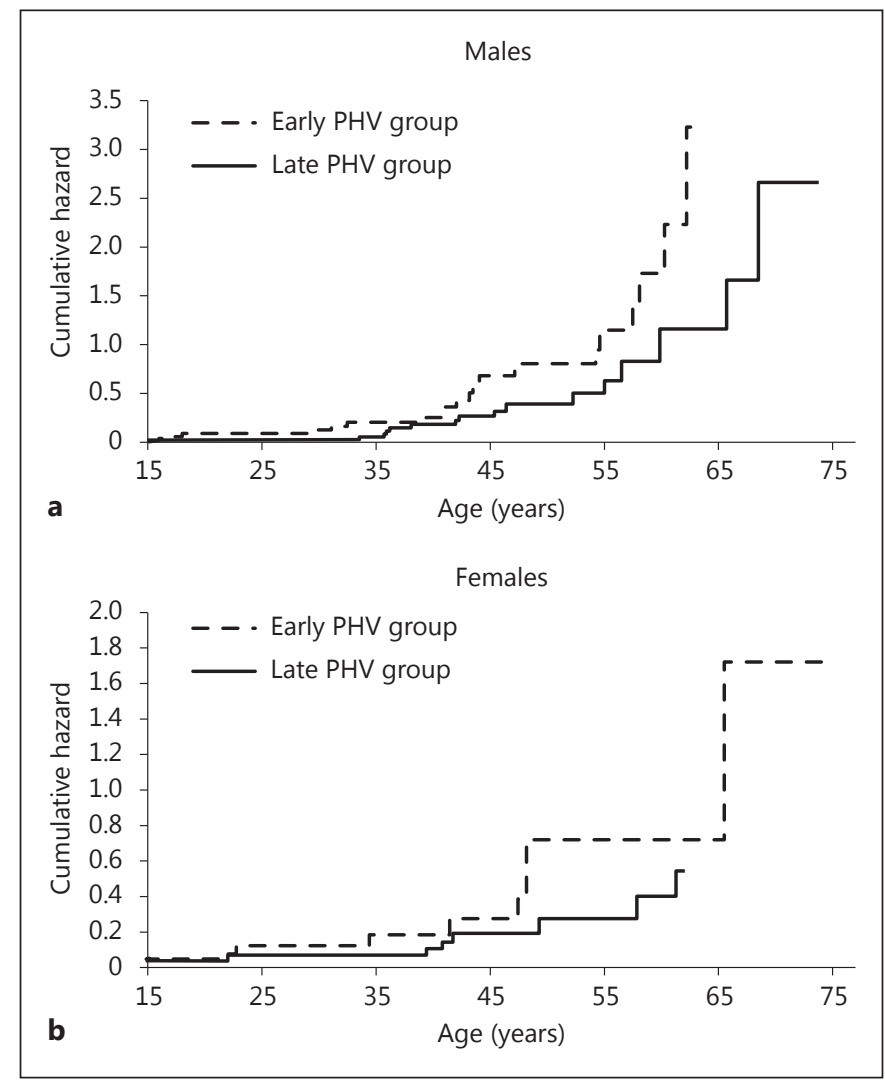

Fig. 5. Cumulative risk of developing impaired fasting plasma glucose concentration for curtailed versus prolonged juvenile state. log-rank: $\mathrm{p}=0.009(\mathbf{a})$ and $\mathrm{p}=0.248$ (b), early vs. late groups.

rial data are relationships that can be revealed by the application of growth curve models and the Kaplan-Meier estimate of the survivor function. The FLS contains information on numerous parameters measured semi-annually in over 2,500 participants for the first 18 years of life and biennially thereafter for decades. Many of the participants are now in their 6th or 7th decades of life and are afflicted with typical age-related chronic conditions. The FLS provides a unique opportunity to characterize accurately the rates and patterns of events during the pubertal growth spurt and to analyze their effects on risk factors for metabolic and cardiovascular diseases later in life.

We previously characterized human growth in height from 2 to 18 years [21]. The pubertal growth spurt in height begins in girls at about 9 or 10 years and in boys at about 10 or 11 years, and the PHV is reached at about 12 years in girls and 14 years in boys $[21,26]$. The mean age of PHV in this sample of the FLS population is $13.5 \pm 1.3$ years for males and $11.5 \pm 0.9$ years for females. The age differences between a slow rate of maturation versus a

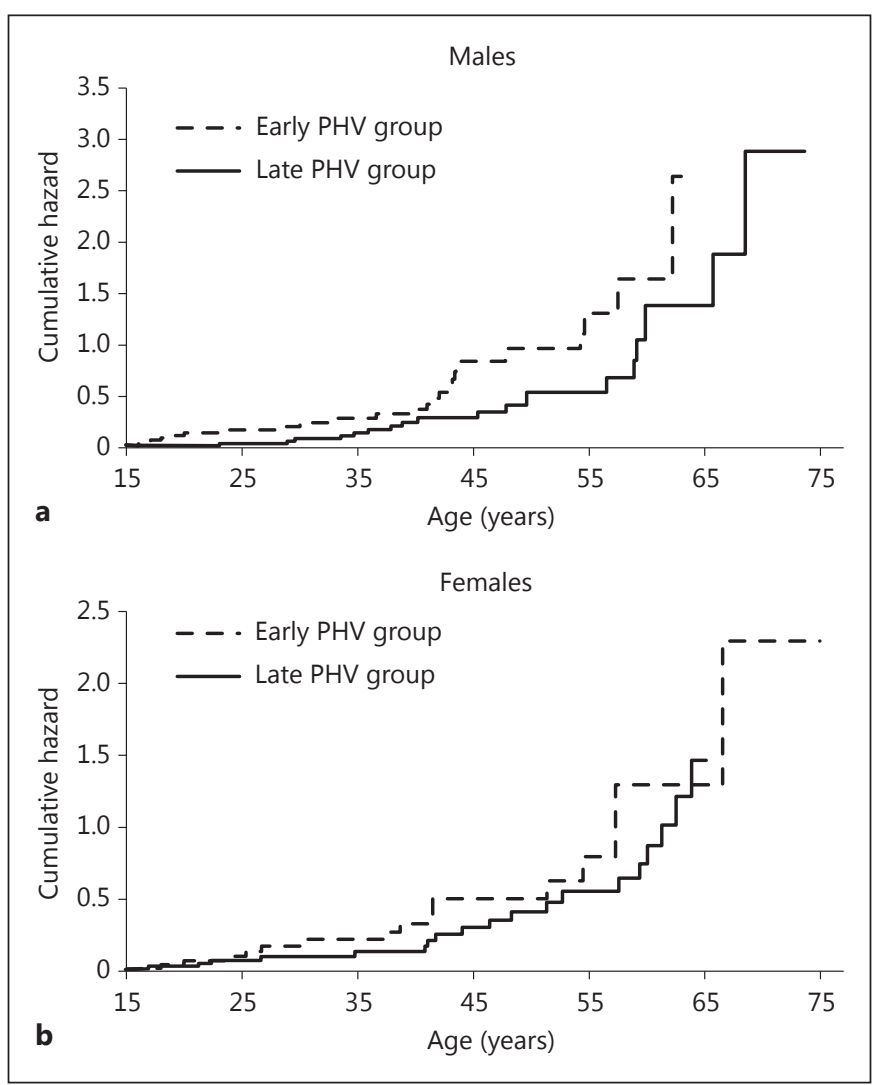

Fig. 6. Cumulative risk of developing dyslipidemia for curtailed versus prolonged juvenile state: triglyerides. $\log$-rank: $\mathrm{p}=0.009$ (a) and $\mathrm{p}=0.527(\mathbf{b})$, early vs. late groups.

rapid rate of maturation are approximately 1.4 year for boys and 1.1 years for girls. Yet, the mean ages at the earliest onset of the metabolic syndrome for the slow versus the rapid maturers was 50.0 versus 43.8 years for men, and 56.4 versus 45.9 years for women. Therefore, this study suggests that the tempo of physiological development affects the onset of the metabolic syndrome.

Reaven [27] reported a clustering of dyslipidemia, hypertension and glucose intolerance, which he named syndrome X. The NCEP ATP III expanded the cluster of risk factors for the syndrome by adding waist circumference, a proxy for visceral fat accumulation [24]. The existence of the metabolic syndrome as a true syndrome, rather than an association of risk factors that covary with obesity, has been debated in the literature $[28,29]$. Sun et al. [30] indicate that the risk factors for the metabolic syndrome operate in concert with or without obesity, and imply the existence of a true syndrome that is not simply a collection of covariates driven by obesity. Using the NCEP ATP III criteria, Ford et al. [31] reported that ap- 


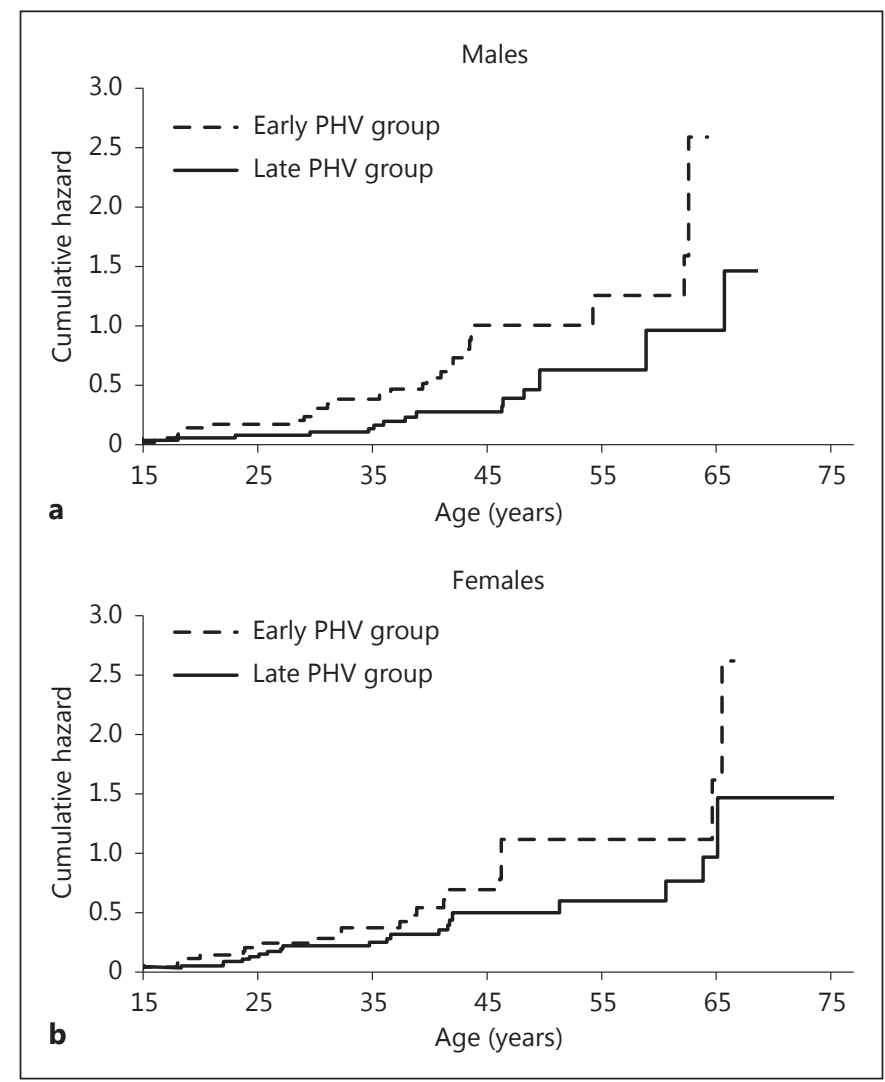

Fig. 7. Cumulative risk of developing dyslipidemia, i.e. low HDL cholesterol for curtailed versus prolonged juvenile state. log-rank: $\mathrm{p}=0.002(\mathbf{a})$ and $\mathrm{p}=0.107(\mathbf{b})$, early vs. late groups.

proximately $24 \%$ of US adults have the metabolic syndrome and that its prevalence is age dependent and sexually dimorphic. These findings agree with ours. However, in the FLS, men $(27.7 \%)$ had a greater prevalence of the metabolic syndrome than women $(20.7 \%)$. The frequency distribution of risk factors that contribute to the metabolic syndrome differs greatly between men and women. The FLS women are more likely than the FLS men to meet the criteria for abdominal obesity and low levels of fasting HDL cholesterol, while the men are more likely than the women to meet the criteria for hypertriglyceridemia, hypertension and impaired fasting glucose.

The impact of the timing of the age at PHV appears to be related to the onset of the metabolic syndrome. These results expand our knowledge on the natural history of the development of obesity, hypertension, dyslipidemia and impaired glucose metabolism, and inform future studies directed at mechanistic relationships. Our findings reveal how the rate of growth in height during childhood may lead either to metabolic and cardiovascular health or dis- ease in adulthood. Elucidating adverse relationships through such a linkage may lead to the early identification of children at high risk for adult cardiovascular disease.

There has been a significant increase in obesity in the US population over the past 25 years. This secular trend toward increasing obesity has also occurred among FLS participants [30]. While there has been an increase in the prevalence of obesity over the course of the FLS, we do not anticipate that the individual biological relationships in rate of maturation and the onset of the metabolic syndrome will have changed as a result of the secular trend toward increased prevalence of obesity.

Although the FLS cohort is not a US population-based sample in terms of race and ethnicity, it is nonetheless a rich and suitable resource for this analysis. The FLS is unique in having serial measurements of hormone levels and direct measurements of body composition on more than 2,500 individuals over a period of 35 years. Although nearly all of the subjects in the FLS are non-Hispanic white, information related to associations investigated in this study is lacking in all racial and ethnic groups. While the results of our analysis will apply to non-Hispanic whites, analysis of this extensive longitudinal data set may also elucidate biological relationships that apply to other races and ethnicities as well as to whites.

\section{Conclusions}

The mean age at PHV in the FLS population is $13.5 \pm$ 1.3 years for boys and $11.5 \pm 0.9$ years for girls. The mean differences between a slow rate of maturation and a rapid rate of maturation are approximately 1.4 years for boys and 1.1 years for girls. Yet, the onset of the metabolic syndrome in males with a slow rate of maturation versus a rapid rate of maturation was 50.0 versus 43.7 years of age, respectively, and 56.4 versus 45.9 years of age for females.

In the FLS, men had a greater prevalence of the metabolic syndrome than women. The frequency distributions of risk factors that contribute to the metabolic syndrome differed greatly between men and women. The FLS women are more likely than the FLS men to meet the criteria for abdominal obesity and low levels of fasting HDL cholesterol, while men are more likely than women to meet the criteria for hypertriglyceridemia, hypertension and impaired fasting glucose.

Females with an early PHV had significantly greater abdominal obesity than those with a late PHV. Males who had an early PHV had an earlier onset of elevated levels of 
fasting plasma glucose, elevated triglycerides and low HDL cholesterol levels ( $p=0.009,0.009$ and 0.002 , respectively). No other differences were observed between the PHV groups and the risk factors for the metabolic syndrome. being considered elsewhere for publication. All authors have been personally and substantially involved in the work leading to the paper, and will hold themselves jointly and individually responsible for its content. In addition, relevant ethical safeguards have been met and the research was approved by an institutional review board.

\section{Disclosure Statement}

We certify that there is no conflict of interest with any financial

organization regarding the material discussed in the manuscript
R01HD060913, R01HD038056, and R01DK071485. This paper contains original material not previously published or currently

\section{Acknowledgement}

This research was funded by R01HL113697, U01HL101064,

\section{References}

$\checkmark 1$ Duan T, Liang MF, Gu SY: Human antiHCMV neutralizing Fab antibody generated by phage display library (in Chinese). Zhonghua Shi Yan He Lin Chuang Bing Du Xue Za Zhi 2003;17:247-250.

-2 Bodkin NL, Alexander TM, Ortmeyer HK, et al: Mortality and morbidity in laboratorymaintained Rhesus monkeys and effects of long-term dietary restriction. J Gerontol A Biol Sci Med Sci 2003;58:212-219.

3 Apfeld J, O'Connor G, McDonagh T, et al: The AMP-activated protein kinase AAK-2 links energy levels and insulin-like signals to lifespan in C. elegans. Genes Dev 2004;18: 3004-3009.

$\checkmark 4$ Beckman KB, Ames BN: The free radical theory of aging matures. Physiol Rev 1998;78: $547-581$.

5 Droge W: Free radicals in the physiological control of cell function. Physiol Rev 2002;82: 47-95.

6 Julian D, Leeuwenburgh C: Linkage between insulin and the free radical theory of aging. Am J Physiol Regul Integr Comp Physiol 2004;286:R20-R21.

7 Sinclair DA: Toward a unified theory of caloric restriction and longevity regulation. Mech Ageing Dev 2005;126:987-1002.

$\checkmark 8$ Keenan KP, Ballam GC, Dixit R, et al: The effects of diet, overfeeding and moderate dietary restriction on Sprague-Dawley rat survival, disease and toxicology. J Nutr 1997; 127(suppl 5):851S-856S.

$\checkmark$ Armitage JA, Taylor PD, Poston L: Experimental models of developmental programming: consequences of exposure to an energy rich diet during development. J Physiol 2005; 565:3-8.

10 Sinha R, Fisch G, Teague B, et al: Prevalence of impaired glucose tolerance among children and adolescents with marked obesity. N Engl J Med 2002;346:802-810.

$\checkmark 11$ Berenson GS, Srinivasan SR, Bao W, et al: Association between multiple cardiovascular risk factors and atherosclerosis in children and young adults. The Bogalusa Heart Study. N Engl J Med 1998;338:1650-1656.
12 Garemo M, Palsdottir V, Strandvik B: Metabolic markers in relation to nutrition and growth in healthy 4-y-old children in Sweden. Am J Clin Nutr 2006;84:1021-1026.

13 Reinehr T, Kiess W, de Sousa G, et al: Intima media thickness in childhood obesity: relations to inflammatory marker, glucose metabolism, and blood pressure. Metabolism 2006;55:113-118.

14 Kaplowitz PB, Slora EJ, Wasserman RC, et al: Earlier onset of puberty in girls: relation to increased body mass index and race. Pediatrics 2001;108:347-353.

15 Himes JH, Obarzanek E, Baranowski T, et al: Early sexual maturation, body composition, and obesity in African-American girls. Obes Res 2004;12(suppl):64S-72S.

16 Lee JM, Appugliese D, Kaciroti N, et al: Weight status in young girls and the onset of puberty. Pediatrics 2007;119:e624-e630.

17 Warren MP, Goodman LR: Exercise-induced endocrine pathologies. J Endocrinol Invest 2003;26:873-878.

18 Warren MP, Shantha S: The female athlete. Baillieres Best Pract Res Clin Endocrinol Metab 2000;14:37-53.

19 Rozé C, Doyen C, Le Heuzey MF, et al: Predictors of late menarche and adult height in children with anorexia nervosa. Clin Endocrinol (Oxf) 2007;67:462-467.

20 Remsburg K, Schubert CM, Chumlea WC, et al: Age at menarche and cardiovascular disease (CVD) risk factors in adolescent girls: the Fels Longitudinal Study. Circulation 2003; 107:34.

21 Sun SS, Schubert C: Prolonged juvenile states and delay of cardiovascular and metabolic risk factors. J Pediatr 2009;155:e1-e6.

22 Lohman GT, Roche AF, Martorell R: Anthropometric Standardization Reference Manual. Champaign, Human Kinetics, 1988.
23 National Heart, Lung and Blood Institute: Manual of Laboratory Operations. I. Lipid and Lipoprotein Analysis. Lipid Research Clinics Program. Bethesda, National Institutes of Health, 1974.

24 National Institute of Health, Executive Summary of the Third Report of the National Cholesterol Education Program Expert Panel on Detection, Evaluation, and Treatment of High Blood Cholesterol in Adults (Adult Treatment Panel III). JAMA 2001;285:2486-2497.

25 Genuth S, Alberti KG, Bennett P, Buse J, Defronzo R, Kahn R, Kitzmiller J, Knowler WC, Lebovitz H, Lernmark A, Nathan D, Palmer J, Rizza R, Saudek C, Shaw J, Steffes M, Stern M, Tuomilehto J, Zimmet P; Expert Committee on the Diagnosis and Classification of Diabetes Mellitus: Follow-up report on the diagnosis of diabetes mellitus. Diabetes Care 2003; 26:3160-3167.

26 Malina RM, Bouchard C, Orded B: Growth, Maturation, and Physical Activity. Chicago, Human Kinetics, 2004.

27 Reaven GM: Banting Lecture 1988. Role of insulin resistance in human disease. Diabetes 1988;37:1595-1607.

28 Kahn R, Buse J, Ferrannini E, Stern M; American Diabetes Association; European Association for the Study of Diabetes: The metabolic syndrome: time for a critical appraisal: joint statement from the American Diabetes Association and the European Association for the Study of Diabetes. Diabetes Care 2005;28: 2289-2304.

29 Cheng AY, Leiter LA: Metabolic syndrome under fire: weighing in on the truth. Can J Cardiol 2006;22:379-382.

- 30 Sun S, Sabo R, Arslanian S, Wu R, Sabo C: Age variation and sexual dimorphism in the sixteen diagnostic clusters of risk factors for the metabolic syndrome. Z Gesundh Wiss 2012; 20:487-497.

- 31 Ford ES, Giles WH, Dietz WH: Prevalence of the metabolic syndrome among US adults: findings from the third National Health and Nutrition Examination Survey. JAMA 2002; 287:356-359. 